\title{
ANÁLISE DE EXPRESSÃO GÊNICA NA IDENTIFICAÇÃO DE POTENCIAIS MARCADORES PREDITIVOS EM NEOPLASIAS MALIGNAS MAMÁRIAS
}

\section{GENE EXPRESSION ANALYSIS IN THE IDENTIFICATION OF POTENTIAL PREDICTIVE MARKERS IN MAMMARY MALIGNANT NEOPLASMS}

\author{
Raissa Monteiro da Silva ${ }^{1}$ \\ Eliane Aline Ribeiro ${ }^{2}$ \\ Abaetê Leite Canto ${ }^{3}$ \\ Luis Henrique Ferreira de Moraes ${ }^{4}$ \\ Renata de Azevedo Canevari ${ }^{5}$
}

\begin{abstract}
Resumo: O status dos linfonodos axilares é o fator prognóstico mais informativo no tratamento das pacientes com câncer de mama. Contudo, atualmente, na prática clínica, a decisão da dissecação dos linfonodos é ainda realizada por meio da biopsia do linfonodo sentinela, o que, muitas vezes, pode trazer sequelas para a paciente ou originar resultados incorretos. Assim, a identificação de marcadores moleculares, na neoplasia maligna primária, que possa permitir uma classificação mais precisa das pacientes em relação à necessidade, ou não, da dissecação dos linfonodos axilares é extremamente importante para uma conduta clínica mais adequada. O objetivo deste estudo foi determinar se os genes SERPINA1, TFF3, TFF1, ARD1A, NGX6 e DKK1 são marcadores preditivos em câncer de mama, pela análise de expressão gênica de RT-qPCR. Para isso, foi comparado o grupo de neoplasias malignas primárias com envolvimento de linfonodos com neoplasias malignas primárias sem linfonodos acometidos, além da análise dos linfonodos correspondentes. Para todos os genes avaliados, apenas o gene TFF1 apresentou expressão diferencial na comparação da neoplasia maligna primária com o linfonodo correspondente, embora não apresentou diferença estatística na comparação da neoplasia maligna primária linfonodo positivo com a neoplasia maligna primária linfonodo negativo. Os resultados obtidos demonstraram que nenhum dos genes avaliados pode ser considerado marcador preditivo em câncer de mama.
\end{abstract}

Palavras-chave: Expressão gênica; linfonodo axilar; câncer de mama.

Abstract: The status of axillary lymph nodes is the most informative prognostic factor in the treatment of patients with breast cancer. However, currently, in clinical practice, the decision to dissect lymph nodes is still performed by sentinel lymph node biopsy, which can often bring consequences to the patient or give incorrect results. Thus, the identification of molecular markers in the primary malignant neoplasm that may allow a more accurate classification of the patients in relation to the necessity or not of axillary lymph node dissection is extremely important for a more adequate clinical management. The aim of this study was to determine if the genes SERPINA1, TFF3, TFF1, ARD1A, NGX6 and DKK1 are predictive markers in breast cancer by the analysis of gene expression of $R T-q P C R$. For this, we compared the group of primary malignant neoplasm with the involvement of lymph nodes and primary malignant neoplasm without affected lymph nodes, in addition to the analysis of the corresponding lymph nodes. For all genes evaluated, only the

\footnotetext{
${ }^{1}$ Laboratório de Bilogia Molecular do Câncer - IP\&D, Universidade do Vale do Paraíba - Univap, SP, Brasil. Email: raissa_monteiro_silva@yahoo.com.br.

2 Laboratório de Bilogia Molecular do Câncer - IP\&D, Universidade do Vale do Paraíba - Univap, SP, Brasil. Email: elianeribeiro319@gmail.com.

3 Centro de Medicina Diagnóstica, São José dos Campos, SP, Brasil. E-mail: abaete@cipax.com.br.

4 Hospital São Francisco de Assis, Departamento de Mastologia, Jacareí, Brasil. E-mail: drluismoraes@hotmail.com.

${ }^{5}$ Laboratório de Bilogia Molecular do Câncer - IP\&D, Universidade do Vale do Paraíba - Univap, SP, Brasil. Email: rcanevari@univap.br.
} 
gene TFF1 presented a differential expression in the comparison of the primary tumor with the corresponding lymph node, although it did not show a statistical difference in the comparison of the positive lymph node primary neoplasm with the negative lymph node primary neoplasm. The results showed that none of the genes analyzed can be considered predictive marker in breast cancer.

Keywords: Gene expression; axillary lymph node; breast cancer.

\section{INTRODUÇÃO}

No planejamento terapêutico, o câncer de mama é a neoplasia maligna mais incidente no mundo e com a maior taxa de mortalidade no gênero feminino (WHO, 2015). Considerando ambos os sexos, essa neoplasia maligna é o segundo tipo de câncer mais frequente no mundo e o mais comum entre as mulheres, sendo considerado a segunda causa de morte por câncer nos países desenvolvidos e a primeira em países em desenvolvimento (WHO, 2015). Segundo o Instituto Nacional do Câncer (INCA), a estimativa do número de casos novos de câncer de mama esperados para a população brasileira, em 2016, é de 57.960 (INSTITUTO..., 2016). Apesar de ser considerado um câncer de bom prognóstico, se diagnosticado e tratado oportunamente, as taxas de mortalidade continuam elevadas, devido a uma alta quantidade de casos ainda diagnosticados em estágios mais evoluídos. Do ponto de vista histológico e genético, essas neoplasias malignas são heterogêneas, constituídas por uma variedade de tipos celulares e apresentando perfis genéticos diferentes mesmo considerando o mesmo tipo histológico (JORNS; SABEL; PANG, 2014).

Pacientes com acometimento de linfonodos são consideradas como um subgrupo de prognóstico desfavorável, ou seja, com uma maior probabilidade de desenvolver metástase em órgãos distantes (MOEBUS et al., 2010). A busca por marcadores moleculares como fatores preditivos do acometimento de linfonodos em câncer de mama auxilia na seleção mais precisa das pacientes nas quais a dissecação dos linfonodos axilares é indicada em relação às pacientes em que esse procedimento é desnecessário (CHENG et al., 2011). Além disso, é importante identificar e determinar se as alterações, na expressão gênica, que ocorrem em metástases de linfonodos axilares regionais são similares à neoplasia maligna primária, para evitar a dissecação total dos linfonodos axilares (SHRIVER; HUEMAN; ELLSWORTH, 2014). Com o advento dos métodos diagnósticos moleculares baseados em PCR, em especial a técnica de PCR quantitativa em tempo real (RT-qPCR), tem sido possível a detecção de marcadores moleculares em neoplasia malignas primárias de câncer de mama com significativo potencial preditivo e prognóstico em relação ao risco de metástases axilares e sistêmicas, respectivamente (KUROSUMI; TAKEI, 2007; SHRIVER; HUEMAN; ELLSWORTH, 2014; CANEVARI et al., 2016).

O objetivo deste estudo consiste em avaliar o potencial preditivo dos genes SERPINA1, TFF3, TFF1, ARD1A, NGX6 e DKK1 em relação ao risco das pacientes com câncer de mama desenvolverem metástases axilares e, assim, auxiliar na seleção mais precisa das pacientes em que a dissecação dos linfonodos axilares é desnecessária. 


\section{METODOLOGIA}

\subsection{Casuística}

Neste estudo, foram utilizadas 51 amostras de neoplasias malignas primárias, obtidas imediatamente após a cirurgia de pacientes com câncer de mama, sendo 28 neoplasias malignas primárias linfonodo negativo, 23 neoplasias malignas primárias linfonodo positivo e 11 amostras de metástases nos linfonodos axilares correspondentes. Duas comparações foram realizadas: na análise 1, foram comparadas amostras de neoplasia primária de pacientes com acometimento de linfonodos versus neoplasia maligna primário de pacientes linfonodo negativo; na análise 2 , foram comparadas as amostras de neoplasia maligna primária com 0 linfonodo correspondente em cada paciente. Amostras de tecido normal foram obtidas de pacientes submetidas à redução mamária e serviram como controle do estudo. As amostras são provenientes do biorrepositório pertencente ao Laboratório de Biologia Molecular do Câncer do Instituto de Pesquisa e Desenvolvimento (IP\&D - UNIVAP). O projeto obteve aprovação do Comitê de Ética da Universidade do Vale do Paraíba ( ${ }^{\circ}$ parecer 1.400.691).

\subsection{Extração do RNA e síntese do cDNA}

A extração do RNA foi realizada segundo o protocolo RNeasy Lipid Tissue (Qiagen). As caracterizações quantitativas e qualitativas das amostras de RNA extraídas foram feitas pela espectroscopia de absorção no ultravioleta, no equipamento NanoDrop (ND-1000 Spectrophotometer v.3.0.1, Labtrade) e eletroforese em gel de agarose a $1 \%$, respectivamente. A síntese de cDNA foi realizada pelo sistema de préamplificação Superscript ${ }^{\mathrm{TM}} I V$, que inclui os reagentes SuperScript ${ }^{\circledR} I V / R_{\text {NaseOUT }}{ }^{\mathrm{TM}}$ Enzyme Mix, 2X First-Strand Reaction Mix, e Buffer de anelamento (Invitrogen, Life Technologies, Carlsbad, CA) (PAULA et al., 2017).

\subsection{Análise de RT-qPCR}

Os iniciadores, para a amplificação dos genes SERPINA1, TFF3, TFF1, ARD1A, NGX6 e DKK1, foram desenhados no software Primer Express (versão 3.0) (PE Applied Biosystems, Foster City, CA, USA) (Tabela 1).

A detecção de alterações de expressão gênica pela RT-qPCR foi realizada no equipamento ABI PRISM 7500 Sequence Detection Systems (Life Technologies, USA). O reagente Platinum $\AA$ SYBR $\Theta$ Green RT-qPCR Super Mix UDG (Applied Biosystems, Life Technologies, Carlsbad, $C A$ ) foi utilizado nas reações de análise de expressão.

Foi realizada a curva padrão, tanto para os genes alvos SERPINA1, TFF3, TFF1, $A R D 1 A, N G X 6$, e DKK1, quanto para o gene endógeno MRLP19, possibilitando o cálculo da eficiência de amplificação dos iniciadores de cada gene bem como a definição da melhor diluição a ser utilizada no experimento. A análise da curva padrão foi realizada pelos valores de slope fornecidos pelo software (Sequence Detection System software, 
versão 2.1, PE Applied Biosystems), os quais estiveram próximos ao valor esperado de -3,3. A curva de dissociação, que avalia a temperatura do pico de amplificação para cada gene versus a intensidade da fluorescência, foi obtida para cada gene, possibilitando averiguar se houve a presença de primer dimere a presença de quaisquer contaminantes na análise. Os thresholds definidos foram os mesmos em todas as corridas de RT-qPCR (VANDESOMPELE et al., 2002).

Tabela 1. Função, tamanho do amplicon e sequência dos iniciadores para os genes alvos e gene endógeno utilizados na análise de RT-qPCR

\begin{tabular}{|c|c|c|c|c|}
\hline Gene & Nome do gene & Função & Amplicons & Sequência dos iniciadores \\
\hline SERPINA1 & $\begin{array}{l}\text { Serpin Family } \\
\text { A Member } 1\end{array}$ & $\begin{array}{l}\text { invasão e } \\
\text { metastáse }\end{array}$ & 63 & $\begin{array}{l}\text { 5'-TGCCAGCTTCATTTACCCAAA-3' } \\
\text { 5'-CCCAGGACGCTCTTCAGATC-3' }\end{array}$ \\
\hline TFF3 & Trefoil Factor 3 & $\begin{array}{c}\text { angiogênese, } \\
\text { proliferação } \\
\text { celular e } \\
\text { invasão } \\
\text { linfática }\end{array}$ & 55 & $\begin{array}{l}\text { 5'-GATTGCTGCCAGGCACTGT-3' } \\
\text { 5'-CTTGCCGGGAGCAAAGG-3' }\end{array}$ \\
\hline TFF1 & Trefoil Factor 1 & $\begin{array}{l}\text { invasão } \\
\text { celular, } \\
\text { resposta ao } \\
\text { estrógeno }\end{array}$ & 60 & $\begin{array}{l}\text { 5'-CATCGACGTCCCTCCAGAA-3' } \\
\text { 5'-CAGGCAGATCCCTGCAGAA-3' }\end{array}$ \\
\hline$A R D 1 A$ & $\begin{array}{c}N(\text { alpha)- } \\
\text { acetyltransfera } \\
\text { se } 10, \text { NatA } \\
\text { catalytic } \\
\text { subunit }\end{array}$ & $\begin{array}{c}\text { metástase, } \\
\text { crescimento } \\
\text { celular, } \\
\text { autofagia e } \\
\text { diferenciação } \\
\text { celular }\end{array}$ & 57 & $\begin{array}{c}\text { 5-CCGCCCTGCACCTCTATTC-3' } \\
\text { 5'-TGGGCTCCACTTCACTGATCT-3' }\end{array}$ \\
\hline$N G \times 6$ & $\begin{array}{l}\text { Transmembran } \\
\text { e Protein } 8 B\end{array}$ & $\begin{array}{c}\text { proliferação } \\
\text { celular, } \\
\text { adesão } \\
\text { celular, } \\
\text { migração e } \\
\text { invasão } \\
\text { celular }\end{array}$ & 58 & $\begin{array}{c}\text { 5'-CCGTGCGCCAGGAAAAC-3' } \\
\text { 5'-CTCAAGGGCACCTCGTGAGT-3' }\end{array}$ \\
\hline$D K K 1$ & $\begin{array}{c}\text { Dickkopf WNT } \\
\text { Signaling } \\
\text { Pathway } \\
\text { Inhibitor } 1\end{array}$ & $\begin{array}{l}\text { Modulador } \\
\text { da Via Wnt, } \\
\text { apoptose e } \\
\text { crescimento } \\
\text { celular }\end{array}$ & 96 & $\begin{array}{l}\text { 5'-TCTGTTTGTCTCCGGTCATCAG-3' } \\
\text { 5'-TCTGTTTGTCTCCGGTCATCAG-3' }\end{array}$ \\
\hline MRLP19 & $\begin{array}{c}\text { Mitochondrial } \\
\text { Ribosomal } \\
\text { Protein L19 }\end{array}$ & $\begin{array}{l}\text { Proteína } \\
\text { ribossomal } \\
\text { mitocondrial } \\
\text { mamária }\end{array}$ & 70 & $\begin{array}{l}\text { 5'-TCTCGACACCTTGTCCTTCGA-3' } \\
\text { '-CAGAGATCAGGAAGAGGACTTGGA-3' }\end{array}$ \\
\hline
\end{tabular}

Fonte: Autores. 


\subsection{Análise dos resultados e análise estatística}

As análises estatísticas que compararam as características clinicopatológicas (idade, tipo histológico, grau histológico, estado de ER, PGR, HER2 e Ki-67 por IHQ (Imunohistoquímica), estadiamento tumoral (com base no Sistema TNM de Classificação dos Tumores Malignos, preconizado pela União Internacional Contra o Câncer - UICC) e tamanho do tumor maligno com a presença ou ausência de envolvimento linfonodal, foram realizadas utilizando o IBM SPSS Software estatístico versão 20.0 e teste qui-quadrado. Os resultados foram considerados, estatisticamente, significativos em $P \leq 0,05$.

A análise da expressão relativa para cada gene alvo e obtenção do $Q R$ (quantificação relativa ou fold change) foi realizada pelo método Delta Delta Ct (PFAFFL, 2001). Os valores médios dos Cts obtidos para os genes alvos foram comparados com a média dos Cts do gene endógeno e, posteriormente, normalizados pela média das amostras normais para a obtenção dos valores de $Q R$.

O QR ou fold change $\left(2^{\wedge}(-\right.$ Delta Delta $\left.\mathrm{Ct})\right)$, que consiste no valor da expressão do gene normalizado $\left(2^{\wedge}(-\right.$ Delta $\left.\mathrm{Ct})\right)$ nas amostras do grupo experimental dividido pela expressão do gene normalizado $\left(2^{\wedge}(-\right.$ Delta $\left.\mathrm{Ct})\right)$, na amostra do grupo controle (tecido normal), foi calculado para cada gene, sendo o resultado expresso pela fórmula: $2^{\wedge}(-$ DDCt). Os valores de fold-change maiores que dois indicam um aumento de expressão para o gene alvo, e o fold-change menor que 0,5 indica diminuição de expressão gênica, com grau de significância de $p$-value $<0,05$ (teste $t$ de Mann Whitney).

\section{RESULTADOS}

\subsection{Características clínico-patológicas}

Em um estudo prévio de nosso grupo (PAULA et al., 2017), no qual se utilizaram as mesmas amostras e critérios de avaliação, que, no presente estudo, foi realizada a análise das características clinico-patológicas das pacientes, cujos resultados obtidos estão descritos na Tabela 2. A idade média das pacientes ao diagnóstico foi de 57 anos (53-60 anos). De acordo com dados clínico-patológicos, 53\% das pacientes apresentavam tumor linfonodo negativo e $47 \%$ linfonodo positivo, com a média de seis linfonodos metastáticos por paciente. A idade média, no momento do diagnóstico, não diferiu, significativamente, entre mulheres que apresentavam metástase linfonodal e as que não apresentavam metástase linfonodal, 53 e 60 anos, respectivamente.

A maioria das amostras foi proveniente de pacientes com carcinoma ductal invasivo (84\%) e a análise pelo sistema TNM foi, predominantemente, T2 (50\%). A maioria das pacientes apresentaram expressão para os marcadores proteicos: ER positivo (80\%), PgR (78\%) e HER2 (50\%) positivo. Duas pacientes foram diagnosticadas com carcinoma mamário em estágio IV; uma paciente veio a óbito; e quatro pacientes 
desenvolveram metástases, após o diagnóstico. Nenhum dos achados patológicos avaliados diferiu, significativamente, entre os grupos (neoplasia maligna primária em mulheres com status de linfonodo negativo e positivo: idade $(P=0,2047)$, tipo histológico ( $P=0,2609)$, grau histológico $(P=1,0000)$, ER $(P=0,6889), \mathrm{PGR}(P=0,4411)$, HER2 $(P=0,2734)$ e Ki-67 $(P=0,4221)$, estadiamento tumoral $(P=0,6492)$ e tamanho do tumor $(P=1,0000)$. Esses resultados indicaram que as características clinicopatológicas das amostras e pacientes analisadas não estão relacionadas à presença ou ausência de metástase linfonodal (Tabela 2).

Tabela 2. Dados clínico-patológicos de 51 amostras de neoplasia maligna de 50 pacientes com carcinomas mamários primários relacionados ao estado de linfonodos axilares

\begin{tabular}{|c|c|c|c|}
\hline Características & $n$ & Linfonodo positivo & $\begin{array}{c}\text { Linfonodo } \\
\text { negativo }\end{array}$ \\
\hline & & $n(\%)$ & $n(\%)$ \\
\hline Idade & 49 & & \\
\hline$\leq 50$ anos & & $9(18 \%)$ & $5(10 \%)$ \\
\hline$>50$ anos & & $14(29 \%)$ & $21(43 \%)$ \\
\hline Histologia & 51 & & \\
\hline Ductal invasivo & & $21(42 \%)$ & $21(42 \%)$ \\
\hline Outros & & $3(6 \%)$ & $6(8 \%)$ \\
\hline Grau histológico & $46^{a}$ & & \\
\hline 1 e 2 & & $13(28 \%)$ & $14(30 \%)$ \\
\hline 3 & & $10(20 \%)$ & $9(18 \%)$ \\
\hline Status do receptor de Estrógeno & $35^{a}$ & & \\
\hline ER - & & $2(6 \%)$ & $5(14 \%)$ \\
\hline $\mathrm{ER}+$ & & $11(31 \%)$ & $17(49 \%)$ \\
\hline $\begin{array}{l}\text { Status do receptor de } \\
\text { Progesterona }\end{array}$ & $45^{a}$ & & \\
\hline PgR - & & $4(9 \%)$ & $6(13 \%)$ \\
\hline $\mathrm{PgR}+$ & & $9(20 \%)$ & $26(58 \%)$ \\
\hline Status do HER2 & $32^{a}$ & & \\
\hline HER2 - & & $4(13 \%)$ & $12(38 \%)$ \\
\hline HER2 + & & $8(25 \%)$ & $8(25 \%)$ \\
\hline Status do Ki67 & $27^{a}$ & & \\
\hline Ki67 (> 25\%) & & $4(15 \%)$ & $5(19 \%)$ \\
\hline Ki67 ( $\leq 25 \%)$ & & $5(19 \%)$ & $13(48 \%)$ \\
\hline $\begin{array}{l}\text { Estadiamento do neoplasia } \\
\text { maligna }\end{array}$ & $48^{a}$ & & \\
\hline T1 e T2 & & $19(40 \%)$ & $24(50 \%)$ \\
\hline T3 e T4 & & $3(6 \%)$ & $2(4 \%)$ \\
\hline Tamanho da neoplasia maligna & $47^{a}$ & & \\
\hline$\leq 2 \mathrm{~cm}$ & & $10(21 \%)$ & $11(23 \%)$ \\
\hline$>2 \mathrm{~cm}$ & & $13(28 \%)$ & $13(28 \%)$ \\
\hline
\end{tabular}

${ }^{a} \mathrm{n}$ total não obtido para esta característica

Fonte: Paula et al. (2017) 


\subsection{Expressão Gênica}

Neste estudo, a expressão dos genes SERPINA1, TFF3, TFF1, ARD1A, NGX6 e $D K K 1$, selecionados a partir do estudo de Shriver, Hueman e Ellsworth (2014), foi avaliada por meio da técnica de RT-qPCR. Duas análises foram realizadas: na análise 1: comparação das amostras de neoplasia maligna primária de pacientes com acometimento de linfonodos versus neoplasia maligna primária de pacientes linfonodo negativo; e análise 2: comparação das amostras de neoplasia maligna primária com o linfonodo correspondente em cada paciente.

Na comparação entre o grupo de pacientes com neoplasia maligna primária sem acometimento de linfonodos ( $\mathrm{n}=28$ amostras) com o grupo de pacientes com neoplasia maligna com envolvimento de linfonodo ( $n=23$ amostras) (Análise 1) não foi detectada diferença significativa para todos os genes avaliados $(P<0,05)$.

Na comparação entre as neoplasias malignas primárias ( $n=11$ amostras) com os linfonodos correspondentes ( $n=11$ amostras) das mesmas pacientes (Análise 2), observou-se diferença significativa apenas para o gene TFF1, que apresentou expressão diminuída no linfonodo em relação ao tumor primário da mesma paciente $(P$ $=0,0209$ ). Nas amostras de neoplasia maligna primária, os níveis de expressão, para esse gene, considerando os valores referência de $Q R$, foram: 0,01 a 0,48 (diminuição de expressão), em três amostras; 2,36 a 336,01 (aumento de expressão), em sete amostras; e 0,5 a 2,0 (expressão normal), em uma amostra. Nas amostras de linfonodos das pacientes, os níveis de expressão, considerando os valores referência de $Q R$, foram: 0,01 a 0,02 (diminuição de expressão), para sete amostras; 13,91 a 297,26 (aumento de expressão), para quatro amostras; e nenhuma amostra apresentou expressão normal.

Os dados referentes às Análises 1 e 2 estão descritos e ilustrados na Tabela 3 e Figuras 3 e 4 .

Tabela 3. Valores de $p$ value referentes à comparação da expressão gênica do grupo de amostras da Análise 1 e da Análise 2 (teste de Mann Whitney).

\begin{tabular}{ccc}
\hline Gene & $p$ value Análise 1 & $p$ value Análise 2 \\
\hline SERPINA1 & 0,3518 & 0,4194 \\
TFF3 & 0,2606 & 0,2540 \\
TFF1 & 0,9124 & 0,0209 \\
ARD1A & 0,4108 & 0,5614 \\
NGX6 & 0,6809 & 0,7089 \\
DKK1 & 0,9727 & 0,0971 \\
\hline
\end{tabular}

Fonte: Autores. 
Figura 3. Comparação entre as médias dos níveis de expressão dos genes

SERPINA1, TFF3, TFF1, ARD1A, NGX6 e DKK1 das neoplasias malignas primárias linfonodo positivo versus linfonodo negativo pela análise de RT-qPCR (Análise 1).
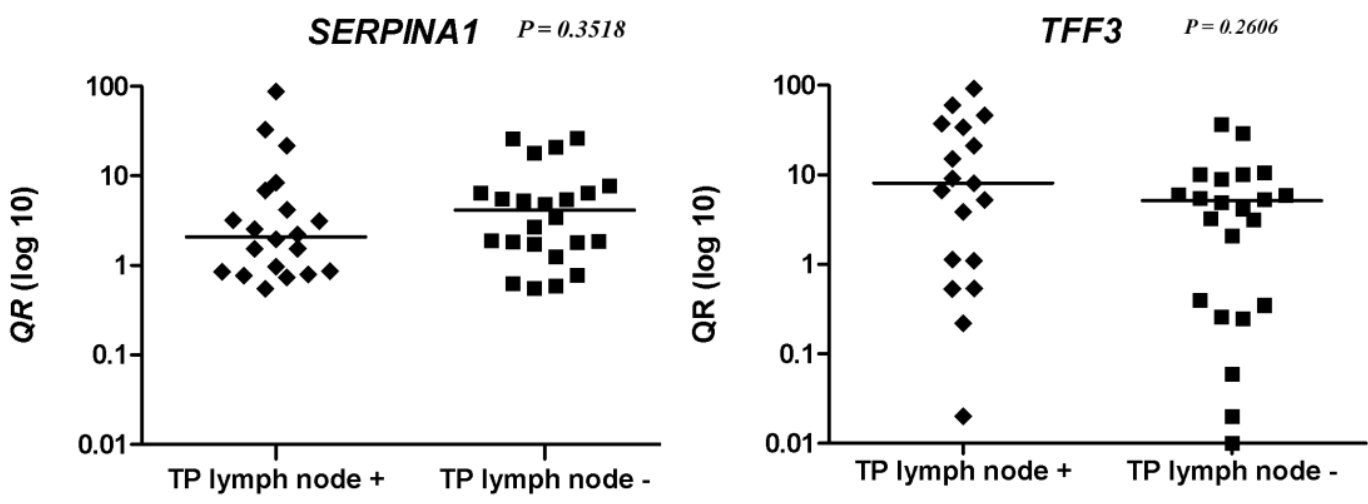

$$
\text { TFF1 } P=0.9124
$$
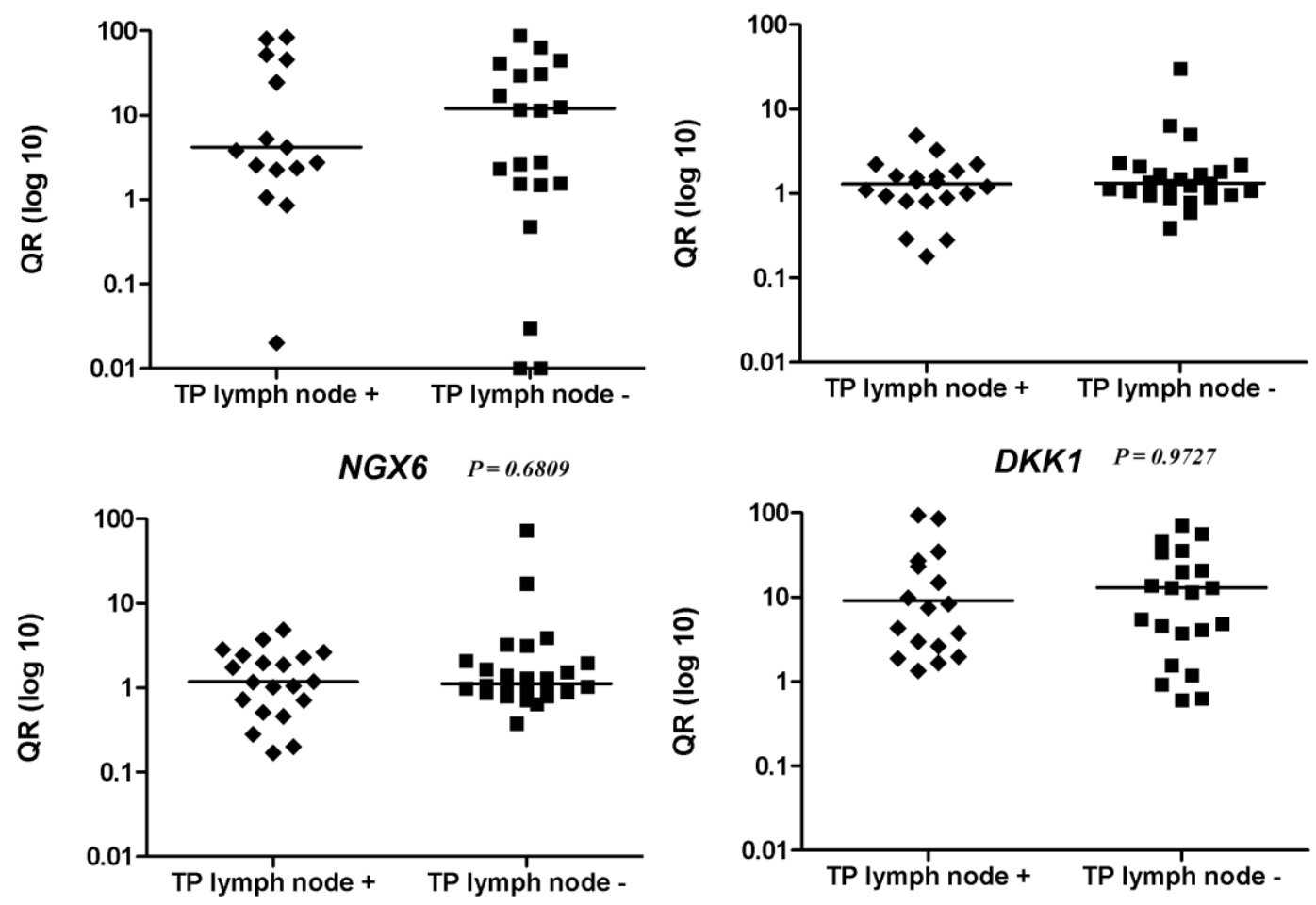

QR: quantificação relativa do gene. TP: neoplasia maligna primária Fonte: Autores. 
Figura 4. Comparação entre as médias dos níveis de expressão dos genes SERPINA1, TFF3, TFF1, ARD1A, NGX6 e DKK1 das neoplasia malignas primárias e linfonodos correspondentes pela análise de RT-qPCR (Análise 2).
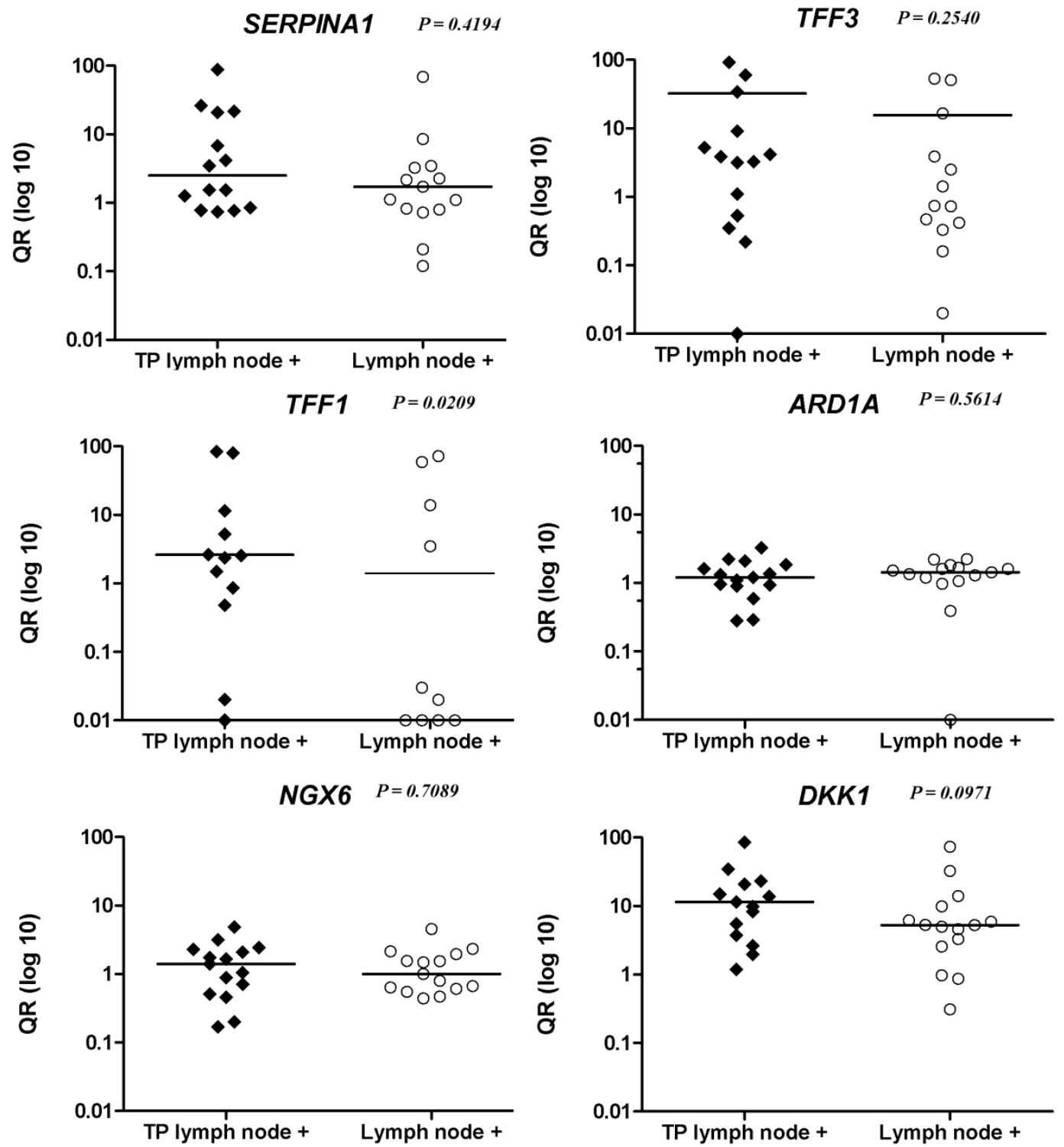

QR: quantificação relativa do gene. TP: neoplasia maligna primária Fonte: Autores.

\section{DISCUSSÃO}

A população brasileira é uma das mais heterogêneas em todo o mundo. Por essa razão, a aplicação de testes moleculares nessa população, tais como a análise de expressão gênica, é extremamente importante, pois pode levar à identificação de marcadores moleculares diagnósticos que são específicos para os tipos de cânceres mais frequentes no Brasil. Além disso, marcadores preditivos e/ou prognósticos também podem ser identificados para determinados tipos tumorais (CANEVARI et al., 2016). 
Sabe-se que a identificação de marcadores preditivos em câncer de mama poderá poupar mulheres com baixo risco de metástase em linfonodos de se submeterem a procedimentos cirúrgicos desnecessários, como a dissecação dos linfonodos axilares (DLN) (VOUTSADAKIS et al., 2015). Contudo, a maioria dos trabalhos de expressão gênica avalia somente o potencial prognóstico dos genes, enquanto uma quantidade reduzida analisa o poder preditivo de genes em amostras de neoplasias primárias e metástases de linfonodos em câncer de mama (BERTUCl et al., 2000; HUANG et al., 2003; ABBA et al., 2007; FENG et al., 2007; WANG et al., 2013; VALENTE et al., 2014; CHEN et al., 2017; PAULA et al., 2017). Além disso, o significado biológico do envolvimento dos linfonodos e sua utilidade na orientação da terapia adjuvante e sistêmica tem sido objeto de muitos resultados discordantes (BERTUCI et al., 2000; HUANG et al., 2003; ABBA et al., 2007).

Embora havendo poucos estudos, se comparado com as assinaturas de marcadores prognósticos, resultados expressivos foram obtidos pelas assinaturas moleculares preditivas por meio da técnica de microarray. Foi possível identificarem-se potenciais genes marcadores preditivos em câncer de mama, que apresentaram expressão diferencial e, com isso, foram capazes de estratificar pacientes com e sem metástase de linfonodos (BERTUCl et al., 2000; HUANG et al., 2003; ABBA et al., 2007; FENG et al., 2007; VALENTE et al., 2014). BERTUCl et al. (2000), utilizando a técnica de microarray, avaliaram a expressão de 176 genes na comparação de neoplasias primárias com metástase de linfonodos e neoplasias primárias sem envolvimento linfonodal, em 34 carcinomas primários de mama. De todos os genes analisados, somente a expressão do gene ERBB2 foi fortemente correlacionada com 0 acometimento dos linfonodos ( $p<0,0001$ ). As características clinico-patológicas observadas por esses autores: idade, tamanho tumoral, tipo e grau histológico, não apresentaram relação estatística significativa quando comparadas com o acometimento de linfonodos nesses pacientes, sendo esse resultado concordante com os nossos achados. Com o objetivo de elucidar o valor preditivo de 70 genes, Huang et al. (2003) detectaram, pelo método de microarray, a expressão de 17 genes preditivos do envolvimento de linfonodos em 89 amostras de neoplasias primárias malignas de mama de pacientes portadoras de metástases linfonodais e/ou recorrência. Em 90\% dos casos avaliados, foram detectados padrões complexos e multivariados de genes associados à recorrência tumoral ou ao envolvimento de linfonodos.

Abba et al. (2007) analisaram assinaturas de expressão gênica por meio da base de dados SAGE em 27 amostras de carcinomas mamários ductal invasivo, com o objetivo de identificar genes relacionados com o envolvimento de linfonodos. Um total de 245 transcritos (55 com expressão elevada e 190 com expressão reduzida) apresentou expressão diferencial nas amostras de tumores primário de pacientes linfonodo positivo em relação a tumores primários linfonodo negativo. Esse estudo sugeriu, assim, que o status dos linfonodos é um dos fatores que está relacionado a perfis de expressão gênica distintos. A validação desses resultados foi obtida pelo 
método de RT-qPCR para os genes HOXC10, TPD52L1, ZFP36L1, PLINP1, DCTN3 $C S N K 1 D$ e $R H B D D 2$, envolvidos em vias de invasão linfonodal, as quais apresentaram expressão elevada nas amostras de neoplasias primárias linfonodo positivo em relação às amostras de neoplasias primárias linfonodo negativo. Esses autores concluíram que, apesar da identificação de genes individuais serem relevantes para a identificação de fatores preditivos, a grande heterogeneidade molecular do câncer de mama requer estudos adicionais na identificação de fatores preditivos mais precisos. Feng et al (2007), identificaram um conjunto de 79 genes diferencialmente expressos na comparação de neoplasias primárias e amostras de metástases de linfonodos pareadas de 26 pacientes utilizando a técnica de microarray. Valente et al (2014), identificaram a expressão diferencial de 22 genes em 20 amostras de neoplasias primárias de pacientes e respectivo metástase linfonodal. Adicionalmente, esses autores compararam linfonodos positivos e negativos, em um total de nove casos cada, por meio desse método. Na primeira análise, foi possível a detecção da expressão elevada nas amostras de linfonodos em 14 genes, incluindo AZGP1, FOXA1 e PIP e, na segunda análise, a detecção de oito genes, tais como o CXCL2 e HPGDS, que apresentaram níveis altos de expressão nos linfonodos não acometidos, sugerindo que esses genes podem ser fortes candidatos a marcadores de recorrência de metástases linfonodais.

Em relação à análise de expressão em genes individuais como potenciais fatores preditivos em tumores mamários, também há poucos estudos publicados na literatura (WANG et al., 2013; SHRIVER; HUEMAN; ELLSWORTH, 2014; PAULA et al., 2017; CHEN et al., 2017). Shriver, Hueman e Ellsworth (2014) detectaram a expressão diferencial dos genes DKK1, IGJ, SCGB1D2, SERPINA1, TFF1, TFF3 e TMSB15A quando compararam neoplasias malignas primárias obtidas de pacientes linfonodo negativo com neoplasias malignas primárias linfonodo positivo, sugerindo esses genes como potenciais marcadores preditivos em câncer de mama. Contudo, neste estudo não foi possível realizar a estratificação das pacientes por meio da avaliação do status do linfonodo com seu respectivo tumor primário (SHRIVER; HUEMAN; ELLSWORTH, 2014). Wang et al (2013) analisaram 30 amostras de câncer de mama a expressão do gene KIF26B pela RT-qPCR, no sentido de elucidar o seu envolvimento na carcinogênese mamária, bem como com o acometimento de linfonodos. Os autores encontraram expressão aumentada para esse gene no tumor primário quando comparado ao tecido adjacente; e relacionaram esse resultado com a proliferação tumoral e envolvimento dos linfonodos. Chen et al (2017) avaliaram a expressão do gene $A H N A K$, envolvido na via de sinalização Wnt, em amostras de carcinoma mamário triplo-negativo no sentido de elucidar o poder prognóstico e preditivo desses genes em câncer de mama. A expressão reduzida observada para o gene AHNAK foi correlacionada negativamente às características clinicopatológicas, tais como tamanho do tumor e envolvimento de linfonodos, concluindo que a expressão reduzida de $A H N A K$ pode ter contribuído para a metástase linfonodal. Esses estudos de análise de expressão gênica pela RT-qPCR comprovam a alta sensibilidade e eficácia desse 
método na identificação da expressão diferencial, sendo, portanto, um método crucial para a identificação de um marcador preditivo no câncer.

No presente estudo, foi analisada a expressão dos genes SERPINA1, TFF3, TFF1, ARD1A, NGX6 e DKK1, previamente identificados por Shriver, Hueman e Ellsworth (2014), para a validação do seu potencial preditivo em neoplasias malignas mamárias de pacientes brasileiras com e sem metástases de linfonodos axilares. Para todos os genes analisados, não foi identificada expressão diferencial significativa quando realizada a Análise 1 (neoplasia maligna primária linfonodo positivo versus neoplasia maligna primária linfonodo negativo). Os resultados obtidos demonstraram que esses genes não podem ser considerados marcadores preditivos nas pacientes acometidas por esses tumores.

Na maioria dos estudos, o status dos genes avaliados é determinado apenas no tumor primário e, de acordo com o nosso conhecimento, poucos estudos têm sido publicados na literatura sobre a avaliação da expressão gênica que comparam os tumores de mama primários e os seus linfonodos correspondentes (FENG et al., 2007; SUZUKI et al., 2007; VECCHI et al., 2008). Os resultados da Análise 2, realizada no presente estudo (neoplasia maligna primária e linfonodos correspondentes), demonstraram que dos seis genes avaliados (SERPINA1, TFF3, TFF1, ARD1A, NGX6 e $D K K 1$ ), apenas o gene TFF1 apresentou expressão diferencial significativa. O gene TFF1 é um gene constitutivo e altamente expresso no tecido do trato gastrointestinal, onde desempenha um importante papel na diferenciação das glândulas gástricas e, também, na proteção da camada mucosa gástrica (BUACHE et al., 2011; MARKICEVIC et al., 2014). Além disso, esse gene também apresenta expressão diferenciada em cânceres, como os de pulmão, ovário, mama, intestino e outras neoplasias (BUACHE et al., 2011; MARKICEVIC et al., 2014). Até o momento, a função de TFF1 durante processos malignos não está claramente definida, ou seja, a elucidação de como a transformação de células epiteliais pode levar a regulação negativa da expressão de TFF1 no câncer gástrico ou a indução da expressão de TFF1 nos demais órgãos (BUACHE et al., 2011; MARKICEVIC et al., 2014). No câncer de mama, é observado que esse gene possui expressão elevada, sugerindo que o TFF1 seja um oncogene, ativando as vias envolvidas na manutenção, invasão celular e angiogênese, além de ser um importante marcador de micro metástases (PERRY et al., 2007; BUACHE et al., 2011). No entanto, contrariamente a esses relatos, alguns estudos descreveram que pacientes com câncer de mama e expressão aumentada do TFF1 apresentaram resposta positiva ao tratamento com o tamoxifeno, pois TFF1 é um gene de resposta ao estrógeno (PERRY et al., 2007; BUACHE et al., 2011; MARKICEVIC et al., 2014).

Várias hipóteses podem explicar a expressão reduzida detectada para o gene TFF1 nos linfonodos axilares quando comparados com a neoplasia primária da mesma paciente. Como apenas uma fração de células localizada em certas regiões do tumor primário apresenta maior potencial metastático (YOKOTA, 2000; ELLSWORTH, 2001) e consequente migração para o linfonodo correspondente, a expressão diferencial 
observada quando comparado o linfonodo versus neoplasia primária, pode ser detectada devido ao número reduzido das células tumorais primárias que se desprenderam e migraram para o linfonodo correspondente. Assim, embora na análise 2 tenha sido detectada a expressão diferencial para o gene TFF1, esse gene não pode ser considerado um marcador molecular preditivo, como comprovado pelos resultados obtidos na Análise 1.

\section{CONCLUSÃO}

Embora os genes avaliados neste estudo tenham sido previamente caracterizados como marcadores preditivos em pacientes com câncer de mama, em nossa busca não houve evidência do seu potencial preditivo. A grande heterogeneidade genética existente na população brasileira pode ser um dos fatores que influenciaram a análise desses genes que estão envolvidos na carcinogênese mamária. Para confirmar esses resultados, faz-se necessário mais estudos com um número maior de casos e, com isso, a obtenção de uma discriminação mais efetiva das pacientes com e sem a propensão de desenvolver metástases em linfonodos.

\section{REFERÊNCIAS}

ABBA, M.C. et al. Breast cancer molecular signatures as determined by SAGE: correlation with lymph node status. Mol Cancer Res. v.5, n. 9, p. 881-890, 2007.

BERTUCCI, F. et al. Gene expression profiling of primary breast carcinomas using arrays of candidate genes. Hum Mol Genet., v. 9, n. 20, p. 2981-2991, 2000.

BUACHE, E. et al. Deficiency in trefoil factor 1 (TFF1) increases neoplasia malignaigenicity of human breast cancer cells and mammary neoplasia maligna development in TFF1-knockout mice. Oncogene- Nature. v. 30, p. 3261-3273, 2011.

CANEVARI, R.A. et al. Identification of novel biomarkers associated with poor patient outcomes in invasive breast carcinoma. Neoplasia maligna Biology. v. 37, n. 10, p. 13855-13870, 2016.

CHEN, B. et al. AHNAK suppresses tumor proliferation and invasion by targeting multiple pathways in triple-negative breast cancer. Journal of Experimental and Clinical Cancer Research, v. 36, n. 65, 2017.

CHENG, G. et al. Current status of sentinel lymphnode biopsy in patients with breast cancer. European Journal of Nuclear Medicine and Molecular Imaging. v. 38, n. 3, p. 562-575, 2011.

ELLSWORTH, R.E. Differencial Gene Expression in Primary Breast Neoplasia malignas Associated with Lymph Node Metastasis. Int J Breast Cancer, v. 2011, p. 17, 2001.

FENG, Y.et al. Differentially expressed genes between primary cancer and paired lymph node metastases predict clinical outcome of node-positive breast cancer patients. Breast Cancer Res Treat., v. 103, n. 3, p. 319-29, 2007. 
HUANG, E. et al. Gene expression predictors of breast cancer outcomes. The Lancet. v. 361, n. 9369, p.1590-1596, 2003.

INSTITUTO NACIONAL DE CÂNCER. Mama. 2016. Disponível em: <http://www2.inca.gov.br/wps/wcm/connect/tiposdecancer/site/home+/mama/cancer_m ama>. Acesso em: 25 jul. 2017.

JORNS, J.; SABEL, M.S.; PANG, J.C. Lobular Neoplasia: Morphology and Management. Archives of Pathology \& Laboratory Medicine. v. 138, n. 10, p. 13441349, 2014.

KUROSUMI, M; TAKEI, H. Significance and problems of histopathological examination and utility of real-time reverse transcriptase polymerase chain reaction method for the detection of sentinel lymph node metastasis in breast cancer. Breast Cancer. v. 14, n. 4, p. 342-349, 2007.

MARKICEVIC, M. et al. Trefoil Factor 1 in Early Breast Carcinoma: A Potential Indicator of Clinical Outcome during the First 3 Years of Follow-Up. International Journal of Medical Sciences., v. 11, n. 7, p. 663-673, 2014.

MOEBUS, V. et al. (Intense dose-dense sequential chemotherapy with epirubicin, paclitaxel, and cyclophosphamide compared with conventionally scheduled chemotherapy in high-risk primary breast cancer: mature results of an AGO phase III study. Journal of Clinical Oncology. v. 28, n. 17, p. 2874-2880, 2010.

NATIONAL CENTER FOR BIOTECHNOLOGY INFORMATION, U.S. NATIONAL LIBRARY OF MEDICINE. GENE. 2017. Disponível em:

<https://www.ncbi.nlm.nih.gov/gene/>. Acesso em: 25 jul. 2017.

PAULA, L.M. et al. Analysis of molecular markers as factors predictive of the involvement on lymph nodes in breast carcinomas. Oncology Letters. v.13, n. 1, p. 488-496, 2017.

PERRY, J.K. et al. Are trefoil factors oncogenic? Trends Endocrinology Metabolism - Cell Press., v. 19, n. 2, p. 74-81, 2007.

PFAFFL, M.W. A new mathematical model for relative quantification in real-time rt-pcr. Nucleic Acids Res., v. 29, n. 45, 2001.

SHRIVER, C.D.; HUEMAN, M.T.; ELLSWORTH, R.E. Molecular signatures of lymph node status by intrinsic subtype: gene expression analysis of primary breast neoplasia maligna from patients with and without metastatic lymph nodes. Journal of

Experimental \& Clinical Cancer Research. v. 33, n. 1, p. 116, 2014.

SUZUKI, M. et al Gene expression profiling of human lymph node metastases and matched primary breast carcinomas: Clinical implications. Mol. Oncol., v.1, n. 2, p. 172-180, 2007.

VALENTE, A. L. et al. Molecular response of the axillary lymph node microenvironment to metastatic colonization. Clin Exp Metastasis., v. 31, n. 5. p. 565-572, 2014.

VANDESOMPELE, J. et al. Accurate normalization of real-time quantitative RT-PCR data by geometric averaging of multiple internal control genes. Genome Biology. v. 3, n. 7, p. 34-34, 2002. 
VECCHI, M. et al. Breast cancer metastases are molecularly distinct from their primary neoplasia malignas. Oncogene., v. 27, n. 15, p. 2148-2158, 2008.

VOUTSADAKIS, I. A; Spadafora, S. Axillary lymph node management in breast cancer with positive sentinel lymph node biopsy. Clinical Oncology. v. 6, n. 1, p. 1-6, 2015.

WANG, Q. et al. High Expression of KIF26B in Breast Cancer Associates with Poor Prognosis. PlosOne, v. 8, n. 4, p. 1-5, 2013.

WHO (World Health Organization). Estimated Cancer Incidence, Mortality and Prevalence Worldwide in 2012. 2015. World Health Organization. Disponível em: <http://globocan.iarc.fr/Default.aspx>. Acesso em: Acesso em: 25 jul. 2017.

YOKOTA, J. Neoplasia maligna progression and mutations. Carcinogenesis. v. 21, n. 3, p. 497-503, 2000. 